\title{
The fall and rise of consciousness science
}

\author{
Anil K. Seth
}

\section{Introduction}

Two out of three central mysteries about our place in the universe have been resolved. The first was literally our place in the universe. Copernicus long ago showed that we weren't at its centre: the Earth is just a speck among the vastness, somewhere "[f]ar out in the uncharted backwaters of the unfashionable end of the western spiral arm of the Galaxy". ${ }^{1}$ The second mystery was resolved by Darwin, who showed with his theory of natural selection that human beings share ancestry with all other species, so that we are just one branch or twig of a beautifully rich and diverse evolutionary tree.

The third mystery, as yet unsolved, concerns the nature and origin of our inner universe consciousness - at once the most familiar and most mysterious aspect of our existence. Conscious experiences define our lives but the private, subjective and intrinsic "what-it-is-likeness" of these experiences seems to resist scientific enquiry. How can the redness-of-red, the warmth of a log fire or the pang of jealousy emerge from physical processes and biological machinery within our brains and bodies?

Consciousness science is the attempt to shed light on, and ultimately resolve, this mystery using the tools of scientific enquiry. The challenge has a prehistory within a variety of intellectual traditions and a more recent history within the modern sciences of psychology and neuroscience. In this

\footnotetext{
${ }^{1}$ D. Adams, The Hitchhiker's Guide to the Galaxy, Basingstoke, Pan Books, 1979.
} 
chapter I will give a brief and necessarily incomplete sketch of this history, finishing by summarising some of the exciting directions driving the next phase of consciousness research.

\section{Defining consciousness}

There is a common view that any scientific explanation of a phenomenon must be preceded by a comprehensive and broadly accepted definition. The history of science has however repeatedly challenged this view, with many phenomena, such as "temperature" and "gene", being continuously redefined as the relevant science advances. A useful measure of scientific progress is the extent to which definitions change from descriptive and phenomenological (eg temperature as the "hotness" of things) to explanatory and mechanistic (temperature as mean molecular kinetic energy). ${ }^{2}$ Having said that, since consciousness (unlike temperature) is intrinsically experiential, any eventual definition is unlikely to exclude phenomenology.

Currently, definitions of consciousness are highly descriptive. While there are diverse candidates, these can be summarised very simply by saying that for a conscious organism there is something it is like to be that organism. ${ }^{3}$ Or one can simply say that consciousness (for humans) is what disappears when we fall into a dreamless sleep and what returns the next morning when we wake up. ${ }^{4}$ Putting things a bit more formally, for conscious organisms there exists a continuous (though interruptible) stream of conscious scenes or experiences - a phenomenal world - which has the character of being subjective and private..$^{5}$

\footnotetext{
${ }^{2}$ H. Chang, Inventing Temperature: Measurement and Scientific Progress, New York, NY, Oxford University Press, 2004.

${ }^{3}$ T. Nagel, 'What is it Like to be a Bat?', Philosophical Review, no. 83, 1974, pp. 435-50.

${ }^{4}$ G. Tononi and C. Koch, 'The Neural Correlates of Consciousness: An Update', Annals of the New York Academy of Sciences, no. 1124, 2008, pp. 239-61.

5 A.K. Seth, 'Editorial', Neuroscience of Consciousness, no. 1, 2015, pp. 1-3.
} 
Beyond these basic statements some further distinctions are useful. The first is between conscious level and conscious content. Conscious level refers to how "conscious" an organism is. As Figure 1 shows, this can be thought of as a graded scale from complete unconsciousness, as in dreamless sleep, coma and deep anaesthesia, all the way to vivid, conscious wakefulness. Importantly, conscious level is not the same as wakefulness or vigilance: one can be conscious while asleep, for example while dreaming, and one can be unconscious while physiologically awake, as happens in sleepwalking and in some pathological conditions such as the vegetative state. ${ }^{6}$

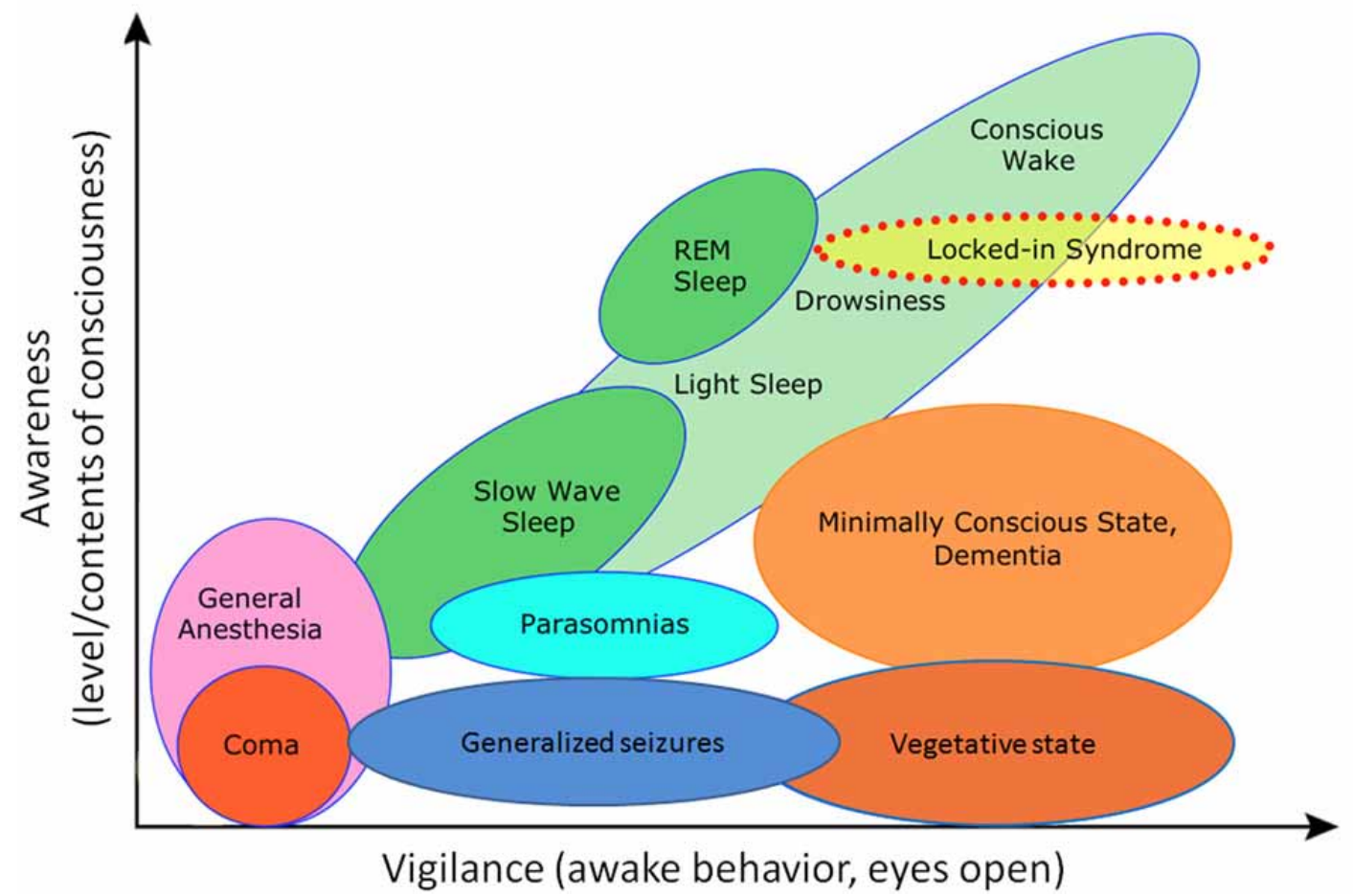

\section{Figure 1: conscious level (awareness) is distinct from, though normally correlated with, physiological wakefulness (vigilance) ${ }^{7}$}

Conscious contents refer to the distinguishable elements of a conscious scene, given a non-zero conscious level. These include consciously experienced colours, shapes, smells, thoughts, explicit beliefs, emotions and moods, experiences of volition and agency, and so on. Collectively, conscious

\footnotetext{
${ }^{6}$ M. Boly et al., 'Consciousness in Humans and Non-human Animals: Recent Advances and Future Directions', Frontiers in Psychology, no. 4, 2013, 625, DOI: 10.3389/fpsyg.2013.00625.

${ }^{7}$ Adapted from Boly et al.
} 
contents are what philosophers call "qualia" and explaining how such "qualitative feeling states" emerge from a physical, material substrate remains the most metaphysically problematic aspect of consciousness science. ${ }^{8}$ Conscious contents can be further divided into those that are world-related, like the smell of freshly cut grass on a summer day, and those that are self-related, like the ache of a rotten tooth or the experience of identifying with and owning a particular body. ${ }^{9}$ Some conscious contents, like the experience of body ownership and of having a first-person perspective on the world, are so continuous and pervasive that it is easy to take them for granted. Yet pathological cases and laboratory experiments show that even these experiences can be altered, meaning that they must be traceable to specific biological mechanisms in the brain. ${ }^{10}$ Any given conscious scene usually integrates elements that are both world-related and self-related, although through the focus of attention one or other may dominate. ${ }^{11}$

Other possible distinctions are less universally accepted. Some researchers distinguish between phenomenal consciousness and access consciousness, where the former relates to all qualitative components of conscious scenes and the latter to just those conscious contents that are available to other cognitive processes, including verbal report. ${ }^{12}$ Although this debate surfaced in the philosophical literature it has important empirical consequences, since the main way of assessing what a person is conscious of is to ask them, which assumes conscious access. While some believe that phenomenal consciousness does not make sense in the absence of access, ${ }^{13}$ others have made persistent efforts to show that unreportable aspects of perception share common perceptual

\footnotetext{
${ }^{8}$ D.J. Chalmers, 'The Puzzle of Conscious Experience', Scientific American, vol. 273, no. 6, 1995, pp. 80-86; R. Kanai and N. Tsuchiya, 'Qualia', Current biology, vol. 22, no. 10, 2012, pp. R392-96, DOI: 10.1016/j.cub.2012.03.033; G. Tononi and C. Koch, 'Consciousness: Here, There and Everywhere?', Philosophical Transactions of the Royal Society of London B: Biological Sciences, vol. 370, no. 1668, 2015, DOI: 10.1098/rstb.2014.0167.

${ }^{9}$ A.K. Seth, 'Interoceptive Inference, Emotion, and the Embodied Self', Trends in Cognitive Sciences, vol. 17, no. 11, 2013, pp. 565-73, DOI: 10.1016/j.tics.2013.09.007.

${ }^{10}$ O. Blanke, M. Slater and A. Serino, 'Behavioral, Neural, and Computational Principles of Bodily SelfConsciousness', Neuron, vol. 88, no. 1, 2015, pp. 145-66, DOI: 10.1016/j.neuron.2015.09.029.

${ }^{11}$ Attention and consciousness, while closely related, are distinguishable - see C. Koch and N. Tsuchiya, 'Attention and Consciousness: Related yet Different', Trends in Cognitive Sciences, vol. 16, no. 2, 2012, pp. 103-05, DOI: 10.1016/j.tics.2011.11.012.

${ }^{12}$ N. Block, 'Two Neural Correlates of Consciousness', Trends in Cognitive Sciences, vol. 9, no. 2, 2005 , pp. 46-52.

${ }^{13}$ S. Dehaene and J.P. Changeux, 'Experimental and Theoretical Approaches to Conscious Processing', Neuron, vol. 70, no. 2, 2011, pp. 200-27, DOI: S0896-6273(11)00258-3 [pii] 10.1016/j.neuron.2011.03.018.
} 
properties with explicitly reportable percepts, suggesting (though not proving) the existence of phenomenal consciousness in the absence of access. ${ }^{14}$

Less controversially, one can distinguish between primary or core consciousness, which refers to first-order, conscious experiences of the world or of the self, and higher-order or reflective consciousness, which refers to "being conscious of being conscious". ${ }^{15}$ This sounds strange but in normal circumstances we are aware of being conscious of this or that. More generally, metacognition (cognition about cognition) is an important element of our psychological make-up. ${ }^{16}$

In summary, definitions of consciousness are needed to specify explanatory targets (or explananda, those phenomena which are to be explained), which can then motivate a search for underlying mechanisms (or explanantia, those causes which do the explaining). In most areas of science, as these mechanisms are revealed, definitions may change from the phenomenological and descriptive to the explanatory and mechanistic. Because consciousness is intrinsically phenomenological, however, its definition will be augmented, not replaced, by causal-mechanistic accounts.

\section{Key questions in consciousness science}

The most fundamental challenge for consciousness science, popularised by David Chalmers as the "hard problem", ${ }^{17}$ is to explain why and how physical processes - such as those unfolding within brains - are ever accompanied by conscious experience. Chalmers contrasts this with the "easy problem" of explaining how the complex biophysical operations of the brain give rise to perception,

\footnotetext{
${ }^{14}$ V.A. Lamme, 'How Neuroscience will Change our View on Consciousness', Cognitive Neuroscience, vol. 1, no. 3, 2010, pp. 204-40.

${ }^{15}$ G.M. Edelman, 'Naturalizing Consciousness: A Theoretical Framework', Proceedings of the National Academy of Sciences of the USA, vol. 100, no. 9, 2003, pp. 5520-24.

${ }^{16}$ S.M. Fleming, R.J. Dolan and C.D. Frith, 'Metacognition: Computation, Biology and Function', Philosophical Transactions of the Royal Society of London B: Biological Sciences, vol. 367, no. 1594, 2012, pp. 1280-86, DOI: 10.1098/rstb.2012.0021.

${ }^{17}$ Chalmers, 'The Puzzle of Conscious Experience'; D.J. Chalmers, 'How Can we Construct a Science of Consciousness?', Annals of the New York Academy of Sciences, no. 1303, 2013, pp. 25-35, DOI: 10.1111/nyas.12166.
} 
action, cognition and behaviour - everything but consciousness! Although some researchers claim that the hard problem can now be solved, ${ }^{18}$ it may anyway be a mistake to view the hard problem as preventing progress in consciousness science. After all, physicists have made great strides in revealing intricate properties of the universe without solving the basic mystery of its existence. ${ }^{19}$ Another useful parallel - though sometimes overplayed - comes from the history of our understanding of life, which at one time may have seemed as mysterious as consciousness does now, but which has nonetheless yielded to a naturalistic explanation that excludes mysterious “explanations" such as an élan vital. ${ }^{20}$

A more tractable goal for consciousness science is to identify the biophysical (predominantly neural) mechanisms that underlie different conscious levels and specific conscious contents. This is the search for the "neural correlates of consciousness", ${ }^{21}$ which has been criticised on the grounds that correlations, by themselves, neither establish causal power nor provide explanations. As we become clearer (through phenomenological investigations) about the diverse aspects of consciousness for which we wish to account, however, and as we identify more detailed potential correlates - also probing their causal status using brain-stimulation methods ${ }^{22}-$ it becomes possible to move from correlation towards explanation. ${ }^{23}$ In this view, consciousness science is primarily about establishing progressively more sophisticated and experimentally validated mappings between subjective, first-person data (the explanatory targets or explananda) and objective, third-

\footnotetext{
${ }^{18}$ Tononi and Koch, 'Consciousness: Here, There and Everywhere?'.

${ }^{19}$ A.K. Seth, 'The Grand Challenge of Consciousness', Frontiers in Psychology, vol. 1, no. 5, 2010, pp. 1-2.

${ }^{20}$ L. Margulis and D. Sagan, What is Life? The Eternal Enigma, London, Weidenfield and Nicolson, 1995.

${ }^{21}$ T. Metzinger (ed.), Neural Correlates of Consciousness: Empirical and Conceptual Questions, Cambridge, MA, MIT Press, 2000; Tononi and Koch, 'The Neural Correlates of Consciousness: An Update'.

${ }^{22}$ T.A. de Graaf, and A.T. Sack, 'Using Brain Stimulation to Disentangle Neural Correlates of Conscious Vision', Frontiers in Psychology, no. 5, 2014, 1019, DOI: 10.3389/fpsyg.2014.01019 (accessed 19 January 2016); A. PascualLeone and V. Walsh, 'Fast Backprojections from the Motion to the Primary Visual Area Necessary for Visual Awareness', Science, vol. 292, no. 5516, 2001, pp. 510-12, DOI: 10.1126/science.1057099.

${ }^{23}$ A.K. Seth, 'Explanatory Correlates of Consciousness: Theoretical and Computational Challenges', Cognitive Computation, vol. 1, no. 1, 2009, pp. 50-63; Tononi and Koch, 'The Neural Correlates of Consciousness: An Update'.
} 
person data (the underlying causal biophysical mechanisms or explanantia, and their behavioural consequences). ${ }^{24}$

This is not the hard problem (it is not about accounting for the existence of consciousness per se) nor the easy problem (it takes phenomenal properties as explananda) - one might instead call it the real problem of consciousness. Seen this way, a major obstacle for consciousness science is not so much the limits of our ability to probe the brain but, rather, to characterise the first-person, phenomenological data that specify appropriate explanatory targets, ${ }^{25}$ so as to carry out effective "neurophenomenology". ${ }^{26}$

Consciousness science has a number of goals besides the basic objective of determining the biophysical basis of conscious experience. These include establishing the function(s) of consciousness: what does consciousness do for an organism? Relevant research involves exploring the limits of unconscious perception ${ }^{27}$ and studying the neural basis of voluntary action. ${ }^{28}$ This generally supports the idea that consciousness enables flexible voluntary behaviour, compared with unconscious or automatic responses.

Other prominent questions in consciousness science have to do with how conscious experiences are altered or lost in pathological conditions in psychiatry (eg in psychosis) and neurology (eg in the vegetative state), and how a fuller understanding of these conditions as disturbances of "normal" consciousness can inform new approaches to diagnosis, prognosis and treatment. ${ }^{29}$ Finally, a mature

\footnotetext{
${ }^{24}$ Seth, 'Editorial'; F. Varela, E. Thompson and E. Rosch, The Embodied Mind: Cognitive Science and Human Experience, Cambridge, MA, MIT Press, 1993.

${ }_{25}$ M. Merleau-Ponty, Phenomenology of Perception, London, Routledge \& Kegan Paul, 1962.

${ }^{26}$ E. Thompson, 'Life and Mind: From Autopoeisis to Neurophenomenology: A Tribute to Francisco Varela', Phenomenology and the Cognitive Sciences, no. 3, 2004, pp. 381-98.

${ }^{27}$ S. van Gaal and V.A. Lamme, 'Unconscious High-level Information Processing: Implication for Neurobiological Theories of Consciousness', Neuroscientist, vol. 18, no. 3, 2012, pp. 287-301, DOI: 10.1177/1073858411404079.

${ }^{28}$ P. Haggard, 'Human Volition: Towards a Neuroscience of Will', Nature Reviews Neuroscience, vol. 9, no. 12, 2008, pp. 934-46.

${ }^{29}$ P.C. Fletcher and C.D. Frith, 'Perceiving is Believing: A Bayesian Approach to Explaining the Positive Symptoms of Schizophrenia', Nature Reviews Neuroscience, vol. 10, no. 1, pp. 48-58, DOI: nrn2536 [pii] 10.1038/nrn2536; A.M.
} 
consciousness science may have things to say about conscious states in preverbal infants ${ }^{30}$ and nonhuman animals, including non-mammals, ${ }^{31}$ and even about the possibility of conscious machines. ${ }^{32}$

\section{A very brief history of consciousness science}

People have been wondering about consciousness since they have been wondering at all. All major religions propose systems of thinking about (or having beliefs about) consciousness and the self. This is not surprising since without consciousness, for any of us, there is simply nothing at all. In the Western rational tradition, explicit theories of consciousness can be traced to Hippocrates ( $\sim 460 \mathrm{BC}-\sim 370 \mathrm{BC})$, now known as the father of modern medicine. Unlike Aristotle (who thought the brain had nothing much to do with consciousness), Hippocrates held that "from nothing else but the brain come joys, delights, laughter and sports, and sorrows, grief, despondency, and lamentations". ${ }^{33}$ This has a deliberate echo in Francis Crick's "astonishing hypothesis" that "[y]ou, your joys and your sorrows, your memories and ambitions, your sense of personal identity and free will, are in fact no more that the behaviour of a vast assembly of nerve cells and their associated molecules". 34

Fast-forward to the Renaissance, when the Belgian physician Andreas Vesalius (1514-64) revolutionised anatomy by performing, and illustrating, the first detailed post-mortem dissections of the human body. His 1543 masterpiece, On the Fabric of the Human Body (a year that also saw Copernicus' On the Revolution of the Celestial Spheres), contains remarkable drawings of the

Owen, N.D. Schiff and S. Laureys, 'A New Era of Coma and Consciousness Science', Progress in Brain Research, no. 177, 2009, pp. 399-411, DOI: 10.1016/S0079-6123(09)17728-2.

${ }^{30}$ S. Kouider et al., 'A Neural Marker of Perceptual Consciousness in Infants', Science, vol. 340, no. 6130, 2013 , pp. 376-80, DOI: $10.1126 /$ science. 1232509.

${ }^{31}$ D.B. Edelman and A.K. Seth, 'Animal Consciousness: A Synthetic Approach', Trends in Neuroscience, vol. 32 , no. 9, 2009, pp. 476-84.

${ }^{32}$ A.K. Seth, 'The Strength of Weak Artificial Consciousness', Journal of Machine Consciousness, vol. 1, no. 1, 2009, pp. 71-82; Tononi and Koch, 'Consciousness: Here, There and Everywhere?'.

${ }^{33}$ From the Hippocratic text 'On the sacred disease', in a translation available at http://classics.mit.edu/Hippocrates/sacred.html (accessed 16 November 2015).

${ }^{34}$ F. Crick, The Astonishing Hypothesis: Scientific Search for the Soul, New York, NY, Simon \& Schuster, 1994. 
structure of the human brain, highlighting some of its most striking features, such as the corpus callosum (the large bundle of nerve fibres connecting the two hemispheres - see Figure 2).
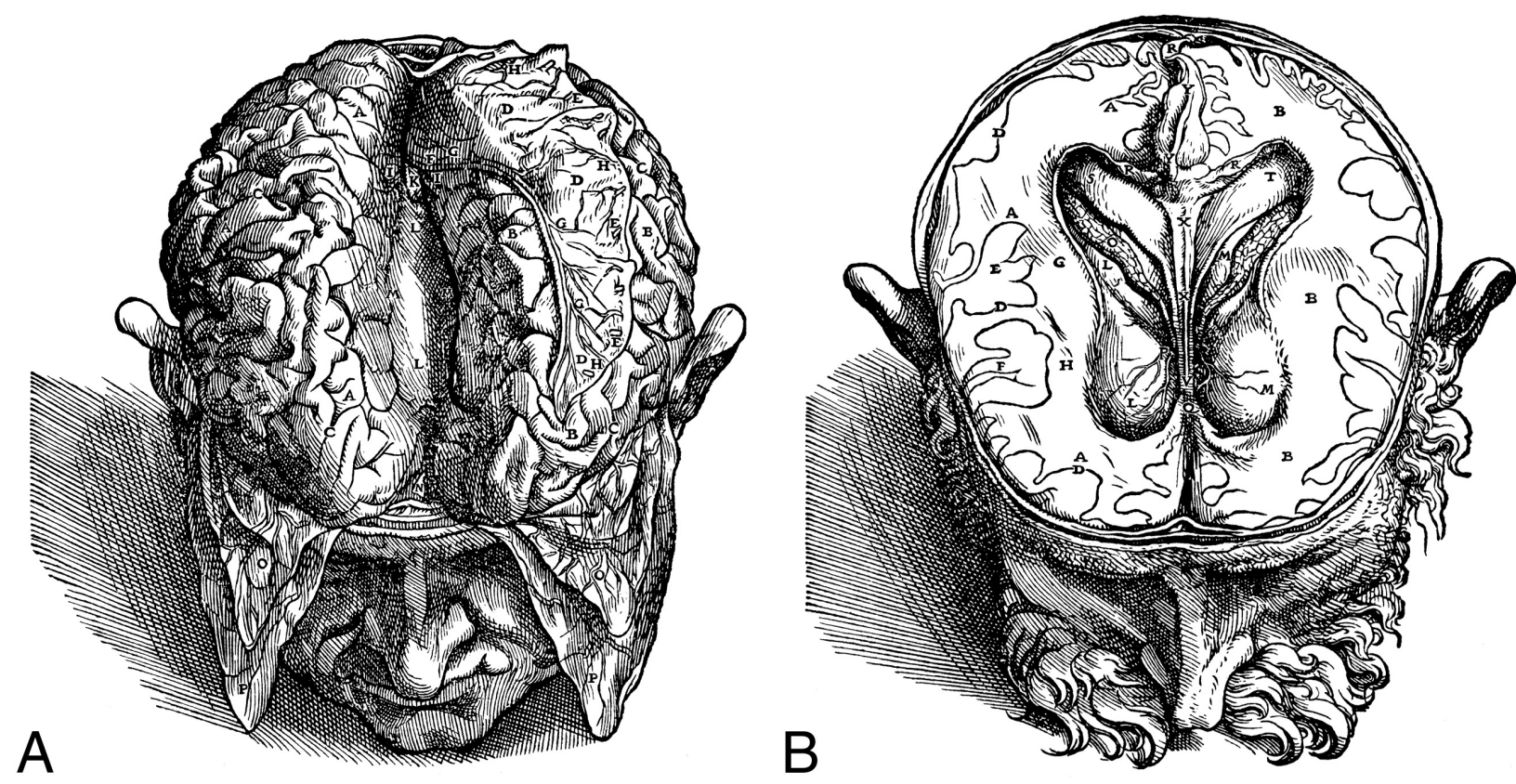

Figure 2: Andreas Vesalius' drawings of the exposed human brain, revealing the corpus callosum in the centre $(A)$ and various cortical gyri and sulci $(B)^{35}$

René Descartes (1596-1650) is usually blamed for inventing the "hard" problem of how consciousness and matter relate, on account of his division of the universe into res cogitans ("mind stuff") and res extensa ("matter stuff"). While his influence on modern science and philosophy is inestimable, he also left a problematic legacy with his "beast machine"” argument - that (nonhuman) animals were mere automatons without "souls" or the ability consciously to suffer.

Moving on a little further, we see some other early statements of the "hard problem". Isaac Newton (1642-1726), studying the physical basis of colour, confessed that " $\mathrm{t}] \mathrm{o}$ determine by what modes or actions light produceth in our minds the phantasm of colour is not so easie". ${ }^{36}$ And Gottfried

\footnotetext{
${ }^{35}$ From De Humani Corpus Fabrica, book VII, 1543.

${ }^{36}$ The quotation is taken from the Stanford Encyclopedia of Philosophy entry on "Panpsychism" - see http://plato.stanford.edu/cgi-bin/encyclopedia/archinfo.cgi?entry=panpsychism (accessed 5 December 2015).
} 
Leibniz put things even more strongly, asserting that "it must be confessed that perception and that which it depends upon are inexplicable on mechanical grounds". 37

The 19th century, especially the latter part, saw the birth of psychology as a science, as well the first steps in what later became neuroscience. The most prominent figures in these developments, with respect to consciousness, are William James (1832-1920) and Wilhelm Wundt (1842-1910), but many other important figures deserve mention: Helmholtz, Charcot, Janet, Broca, Wernicke, Darwin, Galton, Golgi, Mueller, Freud, Donders and Ramon y Cajal, to name but a few. ${ }^{38}$

The legacies of Wundt and James for understanding mind and brain are enormous. Wundt set up the first laboratory of experimental psychology in Leipzig in 1879, while James is still credited with having already said almost everything worth saying about consciousness. ${ }^{39}$ For both, explaining consciousness was at the centre of the new science that became known as psychology.

Wundt believed that consciousness could be best studied using experimental introspection presenting subjects with (for example) ticking metronomes and asking them to report their conscious sensations. This was a highly controlled process in which subjects were extensively trained on how to report their experiences, supporting a scientific rather than casual usage of introspection. Much as chemists disaggregate a complex material into its constituent elements, Wundt believed that conscious experiences could be disaggregated through introspection into component parts. He was searching for the "atoms" of experience.

\footnotetext{
${ }^{37}$ G. Leibniz, The Monadology, 1714, paragraph 17 (Latta translation), available at http://philosophy.eserver.org/leibniz-monadology.txt (accessed 20 January 2016).

${ }_{38}$ The superb treatment in R.M. Young, Mind, Brain, and Adaptation in the Nineteenth Century, New York, NY, Oxford University Press, 1991, has much more on the exciting intellectual currents swirling around early psychology and neuroscience.

${ }^{39}$ W. James, The Principles of Psychology, New York, NY, Henry Holt, 1890.
} 
James rejected the idea that consciousness could be so reduced, coining the phrase "stream of consciousness" to emphasise that conscious experience was a process comprising an ever-changing succession of images, thoughts and feelings. ${ }^{40}$ James' copious writings on psychology and consciousness treated topics as diverse as feelings, desires, emotions, cognitions, beliefs, reasoning and volition - as well as more esoteric subjects like religious experience. ${ }^{41}$ His early writings on attention have been particularly influential and, while he is often thought to have denied a role for unconscious processes, this view seems to rest on misreadings of his Principles. ${ }^{42}$

Around the same time that James and Wundt were initiating the scientific study of mind and consciousness, other intellectual movements were developing which would shape the course of psychology and "consciousness science" in the 20th century. The European phenomenologists, among them Edmund Husserl (1859-1938), provided both a philosophy and a psychology which gave primacy to subjective experience. ${ }^{43}$ This method tried to suspend or "bracket" the preconceptions, interpretations or inferences about conscious experience that may bias introspective report, so that the raw properties of consciousness would become apparent. Sigmund Freud (18561939) focused on the unconscious, proposing theoretical constructs such as the "id", "ego" and "superego", largely on the basis of case studies and self-examination. ${ }^{44}$ Both these disciplines relied primarily on people's introspective reports about their inner lives.

\section{Consciousness in the 20th century: the backlash}

The reliance of early psychology, psychoanalysis and phenomenology on introspection led to a backlash in the early 20th century, the echoes of which are still being felt. Behaviourist psychology,

\footnotetext{
${ }^{40}$ W. James, 'The Stream of Consciousness', in Psychology, Cleveland and New York, World, 1892.

${ }^{41}$ James, The Principles of Psychology; W. James, The Varieties of Religious Experience, London, Longmans, Green \& Co, 1902.

42 J. Weinberger, 'William James and the Unconscious: Redressing a Century-old Misunderstanding', Psychological Science, vol. 11, no. 6, 2000, pp. 439-45.

${ }^{43}$ E. Husserl, Ideas Pertaining to a Pure Phenomenology and to a Phenomenological Philosophy - First Book: General Introduction to a Pure Phenomenology, The Hague, Springer, 1982 [1913]).

${ }^{44}$ S. Freud, The Ego and the Id, Vienna, Internationaler Psychoanalytischer Verlag, 1923.
} 
championed by John B. Watson (1878-1958), argued that introspective data were unreliable, since they could not be objectively validated. Psychology could only become a science if it dealt exclusively with objectively measurable phenomena (behaviour) and dismissed all talk of subjective experiences and even internal, "cognitive" processes ("private events") of any sort. According to Watson's behaviourism, the goal of psychology was not an understanding of the constitution of our mental lives but, rather, the prediction and control of behaviour. ${ }^{45}$

Behaviourism came in several flavours. While Watson believed that private events should be entirely ignored by psychology, B.F. Skinner's "radical behaviourism" acknowledged their existence, although he retained the notion that they could only be studied indirectly, by analysing behavioural data. Both Watson and Skinner were strongly influenced by Ivan Pavlov (1849-1936), who conducted pioneering work on classical conditioning (associating novel stimuli with innate responses) and reflex behaviour - work which Skinner in particular extended into the domain of operant conditioning (linking behavioural cause and effect).

Behaviourism dominated (especially US) psychology throughout the early-to-mid 20th century but is now often treated with some disdain for its systematic neglect of mental content. Yet the behaviourist approach had and continues to have many successes, for instance in restraining some of the excesses of introspectionism and in delivering important insights into learning and memory. ${ }^{46}$ The focus on "prediction and control of behaviour" also motivated an important branch of artificial intelligence, cybernetics, ${ }^{47}$ which is gaining a new relevance within psychology and neuroscience ${ }^{48}$ as the importance of embodiment and physiological regulation becomes increasingly appreciated.

\footnotetext{
${ }^{45}$ J.B. Watson, 'Psychology as the Behaviorist Views it', Psychological Review, no. 20, 1913, pp. 158-77.

${ }^{46}$ W.M. Baum, Understanding Behaviorism: Behavior, Culture, and Evolution, 2nd edn., Hoboken, NJ, WileyBlackwell, 2004.

${ }^{47}$ J.-P. Dupuy, On the Origins of Cognitive Science: The Mechanization of Mind, 2nd edn., Cambridge, MA, MIT Press, 2009.

${ }^{48}$ A.K. Seth, 'The Cybernetic Bayesian Brain: From Interoceptive Inference to Sensorimotor Contingencies', in J.M. Windt and T. Metzinger (eds.), Open MIND, Frankfurt am Main, MIND Group, 2015, pp. 1-24.
} 
Behaviourist methods are still widely used within psychology, but behaviourism as a school of thought faded during the 1960s, as limitations on behaviourist explanation became apparent (notably Chomsky's critiques regarding language) and as cognitive psychology gained prominence. Cognitive psychology was (and still is) based on notions of internal representation and information processing, and its rise in the 1960s was accelerated by its association with developments in classical artificial intelligence.

In seeing the brain as a computer of some sort, however, cognitive psychology remained resistant to addressing consciousness explicitly. "Information processing" can be interpreted as a metaphor for both unconscious and conscious operations, leaving no obvious way to distinguish what is special about consciousness. George Miller, a founder of the field, said in 1962: "We should ban the word consciousness for a decade or two." ${ }^{, 49}$ As late as 1976 another prominent cognitive scientist, Ulrich Neisser, said: "Psychology is not ready for consciousness." ${ }^{, 50}$ (By this time, though, true to his word, Miller was saying: "I consider consciousness to be the constitutive problem of biology." ${ }^{51}$ ) Perhaps the harshest comment of all came from Stuart Sutherland, in the 1989 edition of the International Dictionary of Psychology: "Consciousness is a fascinating but elusive phenomenon. It is impossible to specify what it is, what it does, or why it evolved. Nothing worth reading has been written on it." ${ }^{, 52}$ Early cognitive models, usually consisting of boxes and arrows of different kinds, had entities suggestive of roles for consciousness, but the word itself was never used. ${ }^{53}$

It is tempting to think simply in terms of a progression from Wundt and James, through behaviourism and classical cognitive science, to a turn-of-the-century enlightenment when psychology and neuroscience became reunited, with consciousness once again a central focus.

\footnotetext{
${ }^{49}$ G.A. Miller, Psychology: The Science of Mental Life, New York, NY, Harper \& Row, 1962, p.40.

${ }^{50}$ U. Neisser, Cognition and Reality: Principles and Implications of Cognitive Psychology, New York, NY, Freeman, 1976.

${ }^{51}$ G.A. Miller, 'Computation, Consciousness, and Cognition', Behavioral and Brain Sciences, vol. 3, no. 1, 1980, p. 146.

${ }^{52}$ S. Sutherland, International Dictionary of Psychology, New York, NY, Crossroad Classic, 1989.

${ }^{53}$ M. Boden, Mind as Machine: A History of Cognitive Science, Oxford, Oxford University Press, 2008.
} 
History is of course never so straightforward and the trajectory of consciousness science is more complicated than this simple tale suggests. Even during the heyday of behaviourism, significant work on the brain basis of consciousness was being carried out, the results of which trace directly to the leading edge of consciousness science today.

Hans Berger's invention of the electroencephalograph (EEG) in 1924 is a good example. Berger was the first to record electrical brain activity and in doing so discovered the phenomenon of alpha waves (prominent oscillations at $\sim 10 \mathrm{~Hz}$ which were originally called "Berger waves") and measured their properties in various conditions. A few years later, Alfred Loomis made the first whole-night EEG recordings,${ }^{54}$ laying the foundations for EEG-based sleep staging, and for current attempts to decipher the neurophysiological correlates of conscious level.

Other powerful examples come from neuropsychology, which studies the relationship between brain structure and function, and which pays particular attention to deficits induced by specific and localised brain injury. Paul Broca (1824-80) initiated the field by identifying a region (usually) within the left cortical hemisphere that is critical for language production ("Broca's area"), following observations of patients with aphasia. Neuropsychology came of age during the first world war, which provided under terrible circumstances a ready supply of experimental subjects with focal brain injuries. Soldiers with damage to their visual cortex often presented with specific disturbances in visual experience, providing evidence about the neural basis of visual conscious contents.

In 1957, still well before the rehabilitation of consciousness science, the (clinically motivated) removal of Henry Moliason's hippocampus revealed a direct link between a brain region and the

\footnotetext{
${ }^{54}$ A.L. Loomis, E.N. Harvey and G. Hobart, 'Potential Rhythms of the Cerebral Cortex during Sleep', Science, vol. 81, no. 2111 , 1935, pp. 597-98, DOI: 10.1126/science.81.2111.597.
} 
ability to form new episodic memories, a key part of being a conscious self. ${ }^{55}$ In the late 1950 s and 1960s, Roger Sperry and Michael Gazzaniga pioneered studies of patients who had been treated for intractable epilepsy by severing the corpus callosum. These "split brain" patients showed signs of having two semi-independent "consciousnesses" within a single cranium. ${ }^{56}$ Around the same time, the pioneering Canadian neurosurgeon Wilder Penfield was using electrical brain stimulation to map out the brain's representation of its body (the "cortical homunculus"). Along the way he discovered that stimulating parts of the temporal lobes could induce vivid recall of episodic memories, with other stimulation protocols leading to other specific conscious contents, such as visual hallucinations and experiences of déjà vu. ${ }^{57}$

Nowadays, brain lesion and stimulation studies are key elements of our armamentarium for isolating the necessary and sufficient neural mechanisms underlying conscious contents. While many of these studies still rely on clinical observations and interventions, modern non-invasive techniques, such as transcranial magnetic stimulation (TMS), enable temporary activation and deactivation of specific brain regions in healthy volunteers, boosting the utility of these approaches. $^{58}$

\section{The rebirth of consciousness science}

A convenient date to mark the rehabilitation of consciousness science is with Francis Crick and Christof Koch's landmark 1990 paper, ‘Towards a neurobiological theory of consciousness', which opened with "It is remarkable that most of the work in both cognitive science and the neurosciences makes no reference to consciousness (or 'awareness')" and went on to propose a specific theory

\footnotetext{
${ }^{55}$ W.B. Scoville and B. Milner, 'Loss of Recent Memory after Bilateral Hippocampal Lesions. 1957', Journal of Neuropsychiatry \& Clinical Neurosciences, vol. 12, no. 1, 2000, pp. 103-13.

${ }^{56}$ M.S. Gazzaniga, J.E. Bogen and R.W. Sperry, 'Some Functional Effects of Sectioning the Cerebral Commissures in Man', Proceedings of the National Academy of Sciences of the USA, no. 48, 1962, pp. 1765-69.

57 J. Eccles and W. Feindel, 'Wilder Graves Penfield. 26 January 1891 - 5 April 1976', Biographical Memoirs of Fellows of the Royal Society, no. 24, 1978, pp. 472-513.

${ }^{58}$ de Graaf and Sack, 'Using Brain Stimulation to Disentangle Neural Correlates of Conscious Vision'.
} 
based on $40 \mathrm{~Hz}$ oscillations. ${ }^{59}$ Although this has fallen out of favour, it remains significant in being one of the first neurobiological theories to attempt to draw an explanatory connection between a brain property ( $40 \mathrm{~Hz}$ or "gamma band" oscillations) and a phenomenological property (the binding of disparate visual elements within coherent conscious scenes), while being explicitly phrased as a theory about consciousness.

Crick was not the only prominent Nobel laureate to turn to consciousness, having already established academic immortality. Gerald M. Edelman (1929-2014), who won his Nobel for establishing a selectionist (ie Darwinian) account of immune-system function, had by the early 1990s produced a series of books articulating a similarly selectionist account of brain function, which he called Neural Darwinism (or the "theory of neuronal group selection"). ${ }^{60}$ Consciousness, for Edelman, resulted from massive parallel interactions between brain areas involved in perception and memory, so that conscious scenes comprised a "remembered present". 61

These watersheds in neurobiology were just part of a wider re-emergence of consciousness as a legitimate explanatory target. Movements within philosophy of mind foreshadowed later scientific developments by presenting serious discussions about the possibilities and limitations of brainbased accounts of consciousness. Daniel Dennett caused a stir on publication of Consciousness Explained, ${ }^{62}$ which has since been a little unfairly criticised as "Consciousness Explained Away". A key theme of Dennett's account is that our intuitions about the "specialness" of conscious qualia might be misplaced, creating additional unnecessary mystery.

\footnotetext{
${ }^{59}$ F. Crick and C. Koch, 'Towards a Neurobiological Theory of Consciousness', Seminars in the Neurosciences, no. 2 , 1990, pp. 263-75.

${ }^{60}$ G.M. Edelman, Neural Darwinism: The Theory of Neuronal Group Selection, New York, NY, Basic Books, 1987;

G.M. Edelman, The Remembered Present, New York, NY, Basic Books, 1989.

${ }^{61}$ Edelman, The Remembered Present and 'Naturalizing Consciousness: A Theoretical Framework'; A.K. Seth, 'Darwin's Neuroscientist: Gerald M. Edelman, 1929-2014', Frontiers in Psychology, vol. 5, 2014, 896, DOI: 10.3389/fpsyg.2014.00896.

${ }^{62}$ D. Dennett, Consciousness Explained, Boston, MA, Little, Brown and London, 1991.
} 
Earlier, Tom Nagel and Frank Jackson had tackled the recalcitrant nature of qualia by asking readers to imagine "what it is like to be a bat"63 and to consider the relationship between knowledge (eg about colour vision) and experience (of seeing red). ${ }^{64}$ John Searle's famous "Chinese room" thought experiment, ${ }^{65}$ while originally targeted at the possibility of strong (ie real) artificial intelligence, took things a little further by asking whether simulation of those processes necessary for X (where X might be "translating Chinese" or "seeing red") would be sufficient to instantiate that property.

While these and other philosophers (such as Owen Flanagan and Colin McGinn) were mainly concerned with the possibility of a science of consciousness, others - such as Ned Block and Patricia Churchland - took a more pragmatic attitude, asking how philosophy and science could work together to understand consciousness. Churchland championed the idea of "neurophilosophy", which explores the relevance of neuroscience for philosophy of mind, ${ }^{66}$ and Block introduced the still controversial distinction between "phenomenal" and "access" consciousness, ${ }^{67}$ which continues to inspire fascinating empirical research. ${ }^{68}$

In another influential line, emerging from philosophy, David Rosenthal's "higher order thought" (HOT) theory proposes that a mental state is conscious when a person is aware (or disposed to being aware) of being in that state. Informally, this means that a mental state $\mathrm{X}$ is conscious when there is another mental state Y "pointing at" that first mental state, where Y itself doesn't need to be

\footnotetext{
${ }^{63}$ Nagel, 'What is it Like to be a Bat?'.

${ }^{64}$ F. Jackson, 'Epiphenomenal Qualia', Philosophical Quarterly, no. 32, 1982, pp. 127-36.

65 J. Searle, 'Minds, Brains, and Programs', Behavioral and Brain Sciences, vol. 3, no. 3, 1980, pp. 417-57.

${ }^{66}$ P.S. Churchland, Neurophilosophy: Toward a Unified Science of the Mind-brain, Cambridge, MA, MIT Press, 1986.

${ }^{67}$ N. Block, 'On a Confusion about a Function of Consciousness', Behavioral and Brain Sciences, vol. 18, no. 2, 1995, pp. 227-47 - and see above.

${ }^{68}$ V.A. Lamme, 'How Neuroscience will Change our View on Consciousness', Cognitive Neuroscience, vol. 1, no. 3, 2010, pp. 204-40.
} 
(and typically isn't) conscious. ${ }^{69}$ HOT theories are closely related to studies of metacognition and its role in consciousness. ${ }^{70}$

Contemporary consciousness science also has important origins in cognitive science and artificial intelligence, most notably in the guise of Bernard Baars' "global workspace theory". ${ }^{71}$ Promoted as a "cognitive" theory of consciousness, GWT sees the brain as effecting a network of modular and specialised processors, competing for access to a "global workspace". By analogy with blackboard architectures in artificial intelligence, GWT proposes that mental states become conscious when they are "broadcast" within the global workspace, so that they can influence other more specialised processors, including verbal report and motor actions. On this view, consciousness is mainly about access and has an integrative function - to mobilise and integrate brain operations that are otherwise separate and independent. ${ }^{72}$

Later, brain-based extensions of GWT identified the "workspace" with a tightly interconnected network of frontal and parietal cortical areas, non-linear "ignition" of which corresponded to conscious access. ${ }^{73}$ A wealth of experimental evidence supports this view, to the extent that increased fronto-parietal activity was for many years seen as one of the most reliable correlates of conscious content. ${ }^{74}$ This consensus is however being challenged by recent studies suggesting that such activity (at least the more frontal components) may have more to do with the act of reporting (saying whether or not one is conscious of $\mathrm{X}$ ) than with consciousness per se. $^{75}$

\footnotetext{
${ }^{69}$ D.M. Rosenthal, Consciousness and Mind, Oxford, Clarendon Press, 2005.

${ }^{70}$ S.M. Fleming, R.J. Dolan and C.D. Frith, 'Metacognition: Computation, Biology and Function', Philosophical Transactions of the Royal Society of London B: Biological Sciences, vol. 367, no. 1594, 2012, pp. 1280-86, DOI: $10.1098 /$ rstb.2012.0021.

${ }^{71}$ B.J. Baars, A Cognitive Theory of Consciousness, New York, NY, Cambridge University Press, 1988.

72 B.J. Baars, 'The Conscious Access Hypothesis: Origins and Recent Evidence', Trends in Cognitive Sciences, vol. 6 , no. 1, 2002, pp. 47-52.

${ }^{73}$ S. Dehaene and L. Naccache, 'Towards a Cognitive Neuroscience of Consciousness: Basic Evidence and a Workspace Framework', Cognition, vol. 79, nos. 1-2, 2001, pp. 1-37.

${ }_{75}^{74}$ Dehaene and Changeux, 'Experimental and Theoretical Approaches to Conscious Processing'.

${ }^{75}$ S. Frassle et al., 'Binocular Rivalry: Frontal Activity Relates to Introspection and Action but not to Perception', Journal of Neuroscience, vol. 34, no. 5, 2014, pp. 1738-47, DOI: 10.1523/JNEUROSCI.4403-13.2014; N. Tsuchiya et al., 'No-Report Paradigms: Extracting the True Neural Correlates of Consciousness', Trends in Cognitive Sciences, vol. 19, no. 12, 2015, pp. 757-70, DOI: 10.1016/j.tics.2015.10.002.
} 
Throughout the 1990s, consciousness science was dominated by the search for the neural correlates of consciousness (NCCs). The gold-standard definition of an NCC comes from Crick and Koch, as the "minimal neuronal mechanisms jointly sufficient for any one specific conscious percept". ${ }^{76}$ This approach achieved its dominance for several reasons.

First, the rapid development of brain-imaging methods such as functional MRI made it possible to measure brain activity within the living human brain while volunteers performed specific tasks and while they could report their conscious experiences. Secondly, these technologies (complementing existing methods like EEG) allowed a contrastive analysis of conscious contents, comparing conscious states with closely matched unconscious states in terms of behaviour and neural responses. ${ }^{77}$ Instructive examples of contrastive analysis are found in studies of binocular rivalry, a situation in which one's conscious experience changes even though sensory inputs (different images to each eye) remain constant. ${ }^{78}$ Thirdly, a practical focus on searching for correlates sweeps aside deep metaphysical questions related to the "hard problem", and sidelines even the "real" problem of drawing explanatory links between objective (eg neural) properties and subjective (phenomenal) descriptions. This practical focus also explains why the early explanatory targets for the NCC approach were rather simple and consistent with Crick's attraction to scientific reductionism: the specific conscious percept of "seeing red" was often stated as a canonical example, ${ }^{79}$ yet "redness"

\footnotetext{
${ }^{76}$ Crick and Koch, 'Towards a Neurobiological Theory of Consciousness'.

${ }^{77}$ Baars, 'The Conscious Access Hypothesis: Origins and Recent Evidence'; H.C. Lau and R.E. Passingham, 'Relative Blindsight in Normal Observers and the Neural Correlate of Visual Consciousness', Proceedings of the National Academy of Sciences of the USA, vol. 103, no. 49, 2006, pp. 18763-68.

${ }^{78}$ R. Blake, J. Brascamp and D.J. Heeger, 'Can Binocular Rivalry Reveal Neural Correlates of Consciousness?', Philosophical Transactions of the Royal Society of London B: Biological Sciences, vol. 369, no. 1641, 2014, 20130211, DOI: 10.1098/rstb.2013.0211 (accessed 19 January 2016); D.A. Leopold and N.K. Logothetis, 'Activity Changes in Early Visual Cortex Reflect Monkeys’ Percepts during Binocular Rivalry', Nature, vol. 379, no. 6565, 1966, pp. 54953. This story continues with recent studies, mentioned above, showing that frontal activity sometimes associated with perceptual switches in bistable situations may be due to report rather than to the switch itself (Frassle et al., 'Binocular Rivalry: Frontal Activity Relates to Introspection and Action but not to Perception'). Even more interesting, bistable perceptual switches that are not noticed are not associated with parietal activity (J. Brascamp, R. Blake and T. Knapen, 'Negligible Fronto-parietal BOLD activity Accompanying Unreportable Switches in Bistable Perception', Nature Neuroscience, no. 18, 2015, pp. 1672-78, DOI: 10.1038/nn.4130).

${ }^{79}$ F. Crick and C. Koch, 'A Framework for Consciousness', Nature Neuroscience, vol. 6, no. 2, 2003, pp. 119-26.
} 
as a conscious content makes no sense without the context of a vast repertoire of other actual and counterfactual conscious contents. ${ }^{80}$

A great deal has been learned from the search for NCCs. ${ }^{81}$ By being so conceptually straightforward, by bracketing the hard (and real) problems and by leveraging powerful brainimaging methods, this approach was able rapidly to rehabilitate the study of consciousness within psychology and neuroscience. ${ }^{82}$ Yet in recent years its shortcomings have been more widely recognised, for example in distinguishing any potential NCC “proper” from those neuronal processes that are either prerequisites or inevitable consequences of conscious states. ${ }^{83}$ The need for more sophisticated theories about consciousness, and for a deeper appreciation of the relevant phenomenological explananda, is now motivating a new wave of consciousness science.

\section{Current and future directions}

This chapter has focused on a potted history of consciousness science. In the space remaining, it is only possible to gesture towards some current research directions. ${ }^{84}$

In terms of conscious level, new theories and measures have emerged based on neural complexity and, specifically, "information integration". These ideas advance the field since they are based on phenomenology. The basic idea ${ }^{85}$ is that conscious scenes are both highly "differentiated" (each

\footnotetext{
${ }^{80}$ G. Tononi, 'Consciousness as Integrated Information: A Provisional Manifesto', Biological Bulletin, vol. 215, no. 3, 2008, pp. 216-42.

${ }^{81}$ See Dehaene and Changeux, 'Experimental and Theoretical Approaches to Conscious Processing', and Tononi and Koch, 'The Neural Correlates of Consciousness: An Update', for reviews.

${ }^{82}$ Crick and Koch, 'The Neural Correlates of Consciousness: An Update'; Edelman, 'Naturalizing Consciousness: A Theoretical Framework'.

${ }^{83}$ J. Aru et al., 'Distilling the Neural Correlates of Consciousness', Neuroscience \& Biobehavioral Reviews, vol. 36, no. 2, 2012, pp. 737-46, DOI: 10.1016/j.neubiorev.2011.12.003; T.A. de Graaf, P.J. Hsieh and A.T. Sack, "The "Correlates" in Neural Correlates of Consciousness', Neuroscience \& Biobehavioral Reviews, vol. 36, no. 1, 2012, pp. 191-97, DOI: 10.1016/j.neubiorev.2011.05.012.

${ }^{84}$ See Boly et al., 'Consciousness in Humans and Non-human Animals: Recent Advances and Future Directions', for a reasonably up-to-date survey.

${ }^{85}$ G. Tononi and G.M. Edelman, 'Consciousness and Complexity', Science, vol. 282, no. 5395, 1998, pp. $1846-51$.
} 
conscious scene is one among a vast repertoire of alternative possibilities) and at the same time highly "integrated" (each conscious scene is experienced as a unified whole). The neural dynamics underlying consciousness should therefore also exhibit coexisting integration and differentiation (loosely, "complexity"). Several complexity-based measures of conscious level have been proposed, ${ }^{86}$ which are based on mathematical techniques including information theory and autoregressive time-series modelling. Recently, some complexity-based measures have shown encouraging results in distinguishing different conscious levels, both in healthy volunteers and in neurological patients. ${ }^{87}$ Future work in this area will be especially valuable if it shows that new measures have empirical purchase because of, not despite, being grounded in theory and phenomenology.

Research on conscious content has continued to focus on identifying the brain regions or dynamical processes that distinguish conscious from unconscious perceptions. We have already visited the debate over whether frontal and parietal regions are constitutively involved in conscious perception $^{88}$ - this work is likely to continue with bistable perception remaining a key experimental paradigm. Another classical observation in this area is that "top-down" (also "recurrent", "reentrant”) connections seem necessary for perceptual content to become conscious. ${ }^{89}$ Although a

\footnotetext{
${ }^{86}$ A.K. Seth, A.B. Barrett and L. Barnett, 'Causal Density and Integrated Information as Measures of Conscious Level', Philosophical Transactions of the Royal Society A: Mathematical, Physical, and Engineering Sciences, vol. 369, no. 1952, 2011, pp. 3748-67, DOI: 10.1098/rsta.2011.0079.

${ }^{87}$ A.G. Casali et al., 'A Theoretically Based Index of Consciousness Independent of Sensory Processing and Behavior', Science Translational Medicine, vol. 5, no. 198, 2013, pp. 198ra105, DOI: 10.1126/scitranslmed.3006294 (accessed 19 January 2016); S. Chennu et al., 'Spectral Signatures of Reorganised Brain Networks in Disorders of Consciousness', PLOS Computational Biology, vol. 10, no. 10, 2014, e1003887, DOI: 10.1371/journal.pcbi.1003887 (accessed 19 January 2016); M. Schartner et al., 'Complexity of Multi-Dimensional Spontaneous EEG Decreases during Propofol Induced General Anaesthesia', PLOS One, vol. 10, no 8, 2015, e0133532, DOI: 10.1371/journal.pone.0133532 (accessed 31 January 2016); J.D. Sitt et al., 'Large Scale Screening of Neural Signatures of Consciousness in Patients in a Vegetative or Minimally Conscious State', Brain, vol. 137, pt. 8, 2014, pp. 2258-70, DOI: 10.1093/brain/awu141.

${ }^{88}$ Dehaene and Changeux, 'Experimental and Theoretical Approaches to Conscious Processing'; Tsuchiya et al., 'NoReport Paradigms: Extracting the True Neural Correlates of Consciousness'.

${ }^{89}$ Lamme, 'How Neuroscience will Change our View on Consciousness'; Pascual-Leone and Walsh, 'Fast Backprojections from the Motion to the Primary Visual Area Necessary for Visual Awareness'; H. Super, H. Spekreijse and V.A. Lamme, 'Two Distinct Modes of Sensory Processing Observed in Monkey Primary Visual Cortex (V1)', Nature Neuroscience, vol. 4, no. 3, 2001, pp. 304-10, DOI: 10.1038/85170.
} 
deep understanding of why such top-down activity is necessary remains elusive, one highly promising approach is the so-called "Bayesian brain" or "predictive processing" framework. ${ }^{90}$

On these views, which go back at least as far as Helmholtz in the 19th century, perception is a process of (possibly Bayesian) inference on the hidden causes of the ambiguous and noisy signals that impinge on our sensory surfaces. Top-down signals are suggested to carry perceptual predictions ("priors" in Bayesian terminology) which interact with "bottom up" sensory signals across all levels of the perceptual and motor hierarchies in the brain. The upshot is that perceptual content is determined by the brain's "best guess" of the causes of its sensory signals, corresponding to a Bayesian "posterior".

There is growing evidence that conscious perception can indeed be shaped by top-down predictions or expectations, ${ }^{91}$ and recent neurophysiological studies suggest that top-down and bottom-up signals are carried by distinct cortical frequency bands ${ }^{92}$ in a manner consistent with neurophysiological implementations of the Bayesian brain hypothesis. ${ }^{93}$ While this research is exciting, it remains unknown how and when predictive processing results in conscious perception and, more generally, it is unclear whether the brain actually implements a form of Bayesian inference or whether Bayes' theorem just provides a flexible (perhaps too flexible) framework for conceiving hypotheses about cognitive function. ${ }^{94}$ Future work in this area will likely combine

\footnotetext{
${ }^{90}$ A. Clark, Surfing Uncertainty, Oxford, Oxford University Press, 2016; K.J. Friston, 'The Free-energy Principle: A Unified Brain Theory?', Nature Reviews Neuroscience, vol. 11, no. 2, 2010, pp. 127-38, DOI: nrn2787 [pii] 10.1038/nrn2787; J. Hohwy, The Predictive Mind, Oxford, Oxford University Press, 2013.

${ }^{91}$ L. Melloni et al., 'Expectations Change the Signatures and Timing of Electrophysiological Correlates of Perceptual Awareness', Journal of Neuroscience, vol. 31, no. 4, 2011, pp. 1386-96, DOI: 31/4/1386 [pii] 10.1523/JNEUROSCI.4570-10.2011; Y. Pinto et al., 'Expectations Accelerate Entry of Visual Stimuli into Awareness', Journal of Vision, vol. 15, no. 8, 2015, 13, DOI: 10.1167/15.8.13.

${ }_{92}$ A.M. Bastos et al., 'Visual Areas Exert Feedforward and Feedback Influences Through Distinct Frequency Channels', Neuron, vol. 85, no. 2, 2015, pp. 390-401, DOI: 10.1016/j.neuron.2014.12.018; T. van Kerkoerle et al., 'Alpha and Gamma Oscillations Characterize Feedback and Feedforward Processing in Monkey Visual Cortex', Proceedings of the National Academy of Sciences of the USA, vol. 111, no. 40, 2014, pp. 14332-41, DOI: 10.1073/pnas.1402773111.

${ }^{93}$ K.J. Friston, J. Kilner and L. Harrison, 'A Free Energy Principle for the Brain', Journal of Physiology - Paris, vol. 100, nos. 1-3, 2006, pp. 70-87, DOI: S0928-4257(06)00060-X [pii] 10.1016/j.jphysparis.2006.10.001.

94 J.S. Bowers and C.J. Davis, 'Bayesian Just-so Stories in Psychology and Neuroscience', Psychological Bulletin, vol. 138, no. 3, 2012, pp. 389-414, DOI: $10.1037 / \mathrm{a} 0026450$.
} 
refined conceptual and computational models ${ }^{95}$ with developments in artificial intelligence showing the power of "deep" neural networks for vision and control ${ }^{96}$ and advanced neuroimaging methods,${ }^{97}$ to reveal the conditions and mechanisms governing how perceptual predictions shape conscious contents.

Research on the conscious self distinguishes many levels of experienced selfhood, from a basic embodied selfhood associated with emotion and physiological integrity, through the experience of one's body as a specific object in the world, all the way to higher levels of "narrative" or linguistic selfhood that establish a continuity of the "I" across time. Recent research has advanced understanding in all these areas. For example, it may be possible also to explain the experience of emotional awareness and embodied selfhood from a Bayesian perspective, resting on the brain's best guesses of causes of changes in its own internal physiology, sensed through interoceptive modalities. ${ }^{98}$ These developments recall the earlier ideas of James and Lange, and later Schachter and Singer, ${ }^{99}$ associating emotion with perception of bodily changes, and they make interesting connections with old ideas in "cybernetic" theories of predictive homeostasis. ${ }^{100}$ Strikingly, interoceptive signals - like the heartbeat - can modulate the perception of emotionally salient external stimuli, such as fearful faces. ${ }^{101}$

\footnotetext{
${ }^{95}$ A.K. Seth, 'A Predictive Processing Theory of Sensorimotor Contingencies: Explaining the Puzzle of Perceptual Presence and its Absence in Synesthesia', Cognitive Neuroscience, vol. 5, no. 2, 2014, pp. 97-118, DOI: 10.1080/17588928.2013.877880; C. Summerfield and F.P. de Lange, 'Expectation in Perceptual Decision Making: Neural and Computational Mechanisms', Nature Reviews Neuroscience, vol. 15, no. 11, 2014, pp. 745-56, DOI: $10.1038 / \mathrm{nrn} 3838$.

${ }^{96}$ S.M. Khaligh-Razavi et al., 'The Effects of Recurrent Dynamics on Ventral-stream Representational Geometry', Journal of Vision, vol. 15, no. 12, 2015, 1089, DOI: 10.1167/15.12.1089 (accessed 19 January 2016); V. Mnih et al., 'Human-level Control through Deep Reinforcement Learning', Nature, vol. 518, no. 7540, 2015, pp. 529-33, DOI: 10.1038 /nature 14236.

${ }^{97}$ L. Muckli et al., 'Contextual Feedback to Superficial Layers of V1', Current Biology, vol. 25, no. 20, 2015, pp. 269095, DOI: 10.1016/j.cub.2015.08.057; M. Salti et al., 'Distinct Cortical Codes and Temporal Dynamics for Conscious and Unconscious Percepts', eLife, 2015, DOI: 10.7554/eLife.05652.

${ }^{98}$ L.F. Barrett and W.K. Simmons, 'Interoceptive Predictions in the Brain', Nature Reviews Neuroscience, vol. 16, no. 7, 2015, pp. 419-29, DOI: 10.1038/nrn3950; Seth, 'Interoceptive Inference, Emotion, and the Embodied Self'.

${ }^{99}$ S. Schachter and J.E. Singer, 'Cognitive, Social, and Physiological determinants of Emotional State', Psychological Review, no. 69, 1962, pp. 379-99.

${ }^{100}$ Seth, 'The Cybernetic Bayesian Brain: From Interoceptive Inference to Sensorimotor Contingencies'.

${ }^{101}$ S.N. Garfinkel et al., 'Fear from the Heart: Sensitivity to Fear Stimuli Depends on Individual Heartbeats', Journal of Neuroscience, vol. 34, no. 19, 2014, pp. 6573-82, DOI: 10.1523/JNEUROSCI.3507-13.2014.
} 
Experiences of owning a particular body, and of inhabiting a particular first-person-perspective, are other key aspects of conscious selfhood amenable to a Bayesian account. ${ }^{102}$ These experiences are surprisingly malleable, with simple experimental manipulations able to generate unusual experiences of owning a "rubber hand" or of a shift in one's first-person perspective. ${ }^{103}$

Future work on conscious selfhood will shed new light on how its distinct aspects are integrated into a single unified experience of being "me", perhaps through predictive mechanisms operating at multiple hierarchical levels. This research will capitalise on advances in virtual and augmented reality, which enable dramatic and highly controllable manipulations of self-experience ${ }^{104}$ and may have particular relevance for studies of psychiatric disorders involving disturbances of conscious selfhood. $^{105}$

\section{Conclusions}

The scientific study of consciousness has returned to the forefront of the brain and cognitive sciences. In one sense this is not surprising, since consciousness is the central feature of our mental lives, perhaps of our very existence, and is amenable to experimental manipulation of both its level and content. Yet consciousness was sidelined through much of the previous century as worries about introspection and the intrinsically subjective nature of consciousness held sway. Only time (and more research) will tell whether efforts to solve the "real problem" of explaining conscious

\footnotetext{
${ }^{102}$ M.A. Apps and M. Tsakiris, 'The Free-energy Self: A Predictive Coding Account of Self-recognition', Neuroscience \& Biobehavioral Reviews, vol. 41C, 2014, pp. 85-97, DOI: 10.1016/j.neubiorev.2013.01.029; Blanke, Slater and Serino, 'Behavioral, Neural, and Computational Principles of Bodily Self-Consciousness'; Seth, 'Interoceptive Inference, Emotion, and the Embodied Self'.

${ }^{103}$ O. Blanke and T. Metzinger, 'Full-body Illusions and Minimal Phenomenal Selfhood', Trends in Cognitive Sciences, vol. 13, no. 1, 2009, pp. 7-13, DOI: 10.1016/j.tics.2008.10.003; B. Lenggenhager et al., 'Video Ergo Sum:

Manipulating Bodily Self-consciousness', Science, vol. 317, no. 5841, 2007, pp. 1096-99.

${ }^{104}$ L. Bergouignan, L. Nyberg and H.H. Ehrsson, 'Out-of-body-induced Hippocampal Amnesia', Proceedings of the National Academy of Sciences of the USA, vol. 111, no. 12, 2014, pp. 4421-26, DOI: 10.1073/pnas.1318801111; M. Slater et al., 'First Person Experience of Body Transfer in Virtual Reality', PLOS One, vol. 5, no. 5, 2010, e10564, DOI: 10.1371/journal.pone.0010564.

${ }^{105}$ M. Sierra and A.S. David, 'Depersonalization: A Selective Impairment of Self-awareness', Consciousness and Cognition, vol. 20, no. 1, 2011, pp. 99-108, DOI: 10.1016/j.concog.2010.10.018.
} 
phenomenology in terms of biophysical mechanisms will be successful. Even then, the greater metaphysical mystery of the presence of consciousness in our universe may still remain.

Nevertheless, we already understand a great deal about how conscious level, content and selfhood depend on the brain, body and world. Together, science and philosophy promise many further insights and with them the possibility to understand more - not only about ourselves but about challenging issues regarding consciousness in brain-damaged patients, in infants, in non-human animals and perhaps even in future machines. The future history of consciousness will make for fascinating reading.

Acknowledgements: I am grateful to the Dr Mortimer and Theresa Sackler Foundation, which supports the Sackler Centre for Consciousness Science. I am also grateful to the Ax:son Johnson Foundation for organising the "Return of Consciousness" meeting in Sweden in summer 2015. 


\section{References}

Adams, D., The Hitchhiker's Guide to the Galaxy, Basingstoke, Pan Books, 1979.

Apps, M.A. and M. Tsakiris, 'The Free-energy Self: A Predictive Coding Account of Selfrecognition', Neuroscience \& Biobehavioral Reviews, vol. 41C, 2014, pp. 85-97, DOI:

10.1016/j.neubiorev.2013.01.029.

Aru, J. et al., 'Distilling the Neural Correlates of Consciousness', Neuroscience \& Biobehavioral Reviews, vol. 36, no. 2, 2012, pp. 737-46, DOI: 10.1016/j.neubiorev.2011.12.003.

Baars, B.J., A Cognitive Theory of Consciousness, New York, NY, Cambridge University Press, 1988.

Baars, B.J., 'The Conscious Access Hypothesis: Origins and Recent Evidence', Trends in Cognitive Sciences, vol. 6, no. 1, 2002, pp. 47-52.

Barrett, L.F. and W.K. Simmons, 'Interoceptive Predictions in the Brain', Nature Reviews Neuroscience, vol. 16, no. 7, 2015, pp. 419-29, DOI: 10.1038/nrn3950.

Bastos, A.M. et al., 'Visual Areas Exert Feedforward and Feedback Influences Through Distinct Frequency Channels', Neuron, vol. 85, no. 2, 2015, pp. 390-401, DOI:

10.1016/j.neuron.2014.12.018.

Baum, W.M., Understanding Behaviorism: Behavior, Culture, and Evolution, 2nd edn., Hoboken, NJ, Wiley-Blackwell, 2004. 
Bergouignan, L., L. Nyberg and H.H. Ehrsson, 'Out-of-body-induced Hippocampal Amnesia', Proceedings of the National Academy of Sciences of the USA, vol. 111, no. 12, 2014, pp. 4421-26, DOI: $10.1073 /$ pnas.1318801111.

Blake, R., J. Brascamp and D.J. Heeger, 'Can Binocular Rivalry Reveal Neural Correlates of Consciousness?', Philosophical Transactions of the Royal Society of London B: Biological Sciences, vol. 369, no. 1641, 2014, 20130211, DOI: 10.1098/rstb.2013.0211 (accessed 19 January 2016).

Blanke, O. and T. Metzinger, 'Full-body Illusions and Minimal Phenomenal Selfhood', Trends in Cognitive Sciences, vol. 13, no. 1, 2009, pp. 7-13, DOI: 10.1016/j.tics.2008.10.003.

Blanke, O., M. Slater and A. Serino, 'Behavioral, Neural, and Computational Principles of Bodily Self-Consciousness', Neuron, vol. 88, no. 1, 2015, pp. 145-66, DOI: 10.1016/j.neuron.2015.09.029.

Block, N., 'On a Confusion about a Function of Consciousness', Behavioral and Brain Sciences, vol. 18 , no. 2 , 1995 , pp. $227-47$.

Block, N., 'Two Neural Correlates of Consciousness', Trends in Cognitive Sciences, vol. 9, no. 2, 2005, pp. 46-52.

Boden, M., Mind as Machine: A History of Cognitive Science, Oxford, Oxford University Press, 2008. 
Boly, M. et al., 'Consciousness in Humans and Non-human Animals: Recent Advances and Future Directions', Frontiers in Psychology, no. 4, 2013, 625, DOI: 10.3389/fpsyg.2013.00625.

Bowers, J.S. and C.J. Davis, 'Bayesian Just-so Stories in Psychology and Neuroscience', Psychological Bulletin, vol. 138, no. 3, 2012, pp. 389-414, DOI: 10.1037/a0026450.

Brascamp, J., R. Blake and T. Knapen, 'Negligible Fronto-parietal BOLD activity Accompanying Unreportable Switches in Bistable Perception', Nature Neuroscience, no. 18, 2015, pp. 1672-78, DOI: $10.1038 / \mathrm{nn} .4130$.

Casali, A.G. et al., 'A Theoretically Based Index of Consciousness Independent of Sensory Processing and Behavior', Science Translational Medicine, vol. 5, no. 198, 2013, pp. 198ra105, DOI: 10.1126/scitranslmed.3006294 (accessed 19 January 2016).

Chalmers, D.J., 'The Puzzle of Conscious Experience', Scientific American, vol. 273, no. 6, 1995, pp. 80-86.

Chalmers, D.J., 'How Can we Construct a Science of Consciousness?', Annals of the New York Academy of Sciences, no. 1303, 2013, pp. 25-35, DOI: 10.1111/nyas.12166.

Chang, H., Inventing Temperature: Measurement and Scientific Progress, New York, NY, Oxford University Press, 2004.

Chennu, S. et al., 'Spectral Signatures of Reorganised Brain Networks in Disorders of Consciousness', PLOS Computational Biology, vol. 10, no. 10, 2014, e1003887, DOI: 10.1371/journal.pcbi.1003887 (accessed 19 January 2016). 
Churchland, P.S., Neurophilosophy: Toward a Unified Science of the Mind-brain, Cambridge, MA, MIT Press, 1986.

Clark, A., Surfing Uncertainty, Oxford, Oxford University Press, 2016.

Crick, F., The Astonishing Hypothesis: Scientific Search for the Soul, New York, NY, Simon \& Schuster, 1994.

Crick, F. and C. Koch, 'Towards a Neurobiological Theory of Consciousness', Seminars in the Neurosciences, no. 2, 1990, pp. 263-75.

Crick, F. and C. Koch, 'A Framework for Consciousness', Nature Neuroscience, vol. 6, no. 2, 2003, pp. 119-26.

de Graaf, T.A., P.J. Hsieh and A.T. Sack, 'The “"Correlates"“ in Neural Correlates of Consciousness', Neuroscience \& Biobehavioral Reviews, vol. 36, no. 1, 2012, pp. 191-97, DOI: 10.1016/j.neubiorev.2011.05.012.

de Graaf, T.A. and A.T. Sack, 'Using Brain Stimulation to Disentangle Neural Correlates of Conscious Vision', Frontiers in Psychology, no. 5, 2014, 1019, DOI: 10.3389/fpsyg.2014.01019 (accessed 19 January 2016).

Dehaene, S. and J.P. Changeux, 'Experimental and Theoretical Approaches to Conscious Processing', Neuron, vol. 70, no. 2, 2011, pp. 200-27, DOI: S0896-6273(11)00258-3 [pii] 10.1016/j.neuron.2011.03.018. 
Dehaene, S. and L. Naccache, 'Towards a Cognitive Neuroscience of Consciousness: Basic Evidence and a Workspace Framework', Cognition, vol. 79, nos. 1-2, 2001, pp. 1-37.

Dennett, D., Consciousness Explained, Boston, MA, Little, Brown and London, 1991.

Dupuy, J.-P., On the Origins of Cognitive Science: The Mechanization of Mind, 2nd edn., Cambridge, MA, MIT Press, 2009.

Eccles, J. and W. Feindel, 'Wilder Graves Penfield. 26 January 1891 - 5 April 1976', Biographical Memoirs of Fellows of the Royal Society, no. 24, 1978, pp. 472-513.

Edelman, D.B. and A.K. Seth, 'Animal Consciousness: A Synthetic Approach', Trends in Neuroscience, vol. 32, no. 9, 2009, pp. 476-84.

Edelman, G.M., Neural Darwinism: The Theory of Neuronal Group Selection, New York, NY, Basic Books, 1987.

Edelman, G.M., The Remembered Present, New York, NY, Basic Books, 1989.

Edelman, G.M., 'Naturalizing Consciousness: A Theoretical Framework', Proceedings of the National Academy of Sciences of the USA, vol. 100, no. 9, 2003, pp. 5520-24.

Fleming, S.M., R.J. Dolan and C.D. Frith, 'Metacognition: Computation, Biology and Function', Philosophical Transactions of the Royal Society of London B: Biological Sciences, vol. 367, no. 1594, 2012, pp. 1280-86, DOI: 10.1098/rstb.2012.0021. 
Fletcher, P.C. and C.D. Frith, 'Perceiving is Believing: A Bayesian Approach to Explaining the Positive Symptoms of Schizophrenia', Nature Reviews Neuroscience, vol. 10, no. 1, pp. 48-58, DOI: nrn2536 [pii] 10.1038/nrn2536.

Frassle, S. et al., 'Binocular Rivalry: Frontal Activity Relates to Introspection and Action but not to Perception', Journal of Neuroscience, vol. 34, no. 5, 2014, pp. 1738-47, DOI:

10.1523/JNEUROSCI.4403-13.2014.

Freud, S., The Ego and the Id, Vienna, Internationaler Psychoanalytischer Verlag, 1923.

Friston, K.J., 'The Free-energy Principle: A Unified Brain Theory?', Nature Reviews Neuroscience, vol. 11, no. 2, 2010, pp. 127-38, DOI: nrn2787 [pii] 10.1038/nrn2787.

Friston, K.J., J. Kilner and L. Harrison, ‘A Free Energy Principle for the Brain’, Journal of Physiology-Paris, vol. 100, nos. 1-3, 2006, pp. 70-87, DOI: S0928-4257(06)00060-X [pii] 10.1016/j.jphysparis.2006.10.001.

Garfinkel, S.N. et al., 'Fear from the Heart: Sensitivity to Fear Stimuli Depends on Individual Heartbeats', Journal of Neuroscience, vol. 34, no. 19, 2014, pp. 6573-82, DOI: 10.1523/JNEUROSCI.3507-13.2014.

Gazzaniga, M.S., J.E. Bogen and R.W. Sperry, 'Some Functional Effects of Sectioning the Cerebral Commissures in Man', Proceedings of the National Academy of Sciences of the USA, no. 48, 1962, pp. 1765-69. 
Haggard, P., 'Human Volition: Towards a Neuroscience of Will', Nature Reviews Neuroscience, vol. 9 , no. 12 , 2008, pp. 934-46.

Hohwy, J., The Predictive Mind, Oxford, Oxford University Press, 2013.

Husserl, E., Ideas Pertaining to a Pure Phenomenology and to a Phenomenological PhilosophyFirst Book: General Introduction to a Pure Phenomenology, The Hague, Springer, 1982 [1913]).

Jackson, F., 'Epiphenomenal Qualia', Philosophical Quarterly, no. 32, 1982, pp. 127-36.

James, W., The Principles of Psychology, New York, NY, Henry Holt, 1890.

James, W., 'The Stream of Consciousness', in Psychology, Cleveland and New York, World, 1892.

James, W., The Varieties of Religious Experience, London, Longmans, Green \& Co, 1902.

Kanai, R. and N. Tsuchiya, 'Qualia', Current biology, vol. 22, no. 10, 2012, pp. R392-96, DOI: 10.1016/j.cub.2012.03.033.

Khaligh-Razavi, S.M. et al., 'The Effects of Recurrent Dynamics on Ventral-stream Representational Geometry', Journal of Vision, vol. 15, no. 12, 2015, 1089, DOI: 10.1167/15.12.1089 (accessed 19 January 2016).

Koch, C. and N. Tsuchiya, 'Attention and Consciousness: Related yet Different', Trends in Cognitive Sciences, vol. 16, no. 2, 2012, pp. 103-05, DOI: 10.1016/j.tics.2011.11.012. 
Kouider, S. et al., 'A Neural Marker of Perceptual Consciousness in Infants', Science, vol. 340, no. 6130, 2013, pp. 376-80, DOI: 10.1126/science.1232509.

Lamme, V.A., 'How Neuroscience will Change our View on Consciousness', Cognitive Neuroscience, vol. 1, no. 3, 2010, pp. 204-40.

Lau, H.C. and R.E. Passingham, 'Relative Blindsight in Normal Observers and the Neural Correlate of Visual Consciousness', Proceedings of the National Academy of Sciences of the USA, vol. 103, no. 49,2006 , pp. 18763-68.

Lenggenhager, B. et al., 'Video Ergo Sum: Manipulating Bodily Self-consciousness', Science, vol. 317, no. 5841, 2007, pp. 1096-99.

Leopold, D.A. and N.K. Logothetis, 'Activity Changes in Early Visual Cortex Reflect Monkeys' Percepts during Binocular Rivalry', Nature, vol. 379, no. 6565, 1966, pp. 549-53.

Loomis, A.L., E.N. Harvey and G. Hobart, 'Potential Rhythms of the Cerebral Cortex during Sleep', Science, vol. 81, no. 2111, 1935, pp. 597-98, DOI: 10.1126/science.81.2111.597.

Margulis, L. and D. Sagan, What is Life? The Eternal Enigma, London, Weidenfield and Nicolson, 1995.

Melloni, L. et al., 'Expectations Change the Signatures and Timing of Electrophysiological Correlates of Perceptual Awareness', Journal of Neuroscience, vol. 31, no. 4, 2011, pp. 1386-96, DOI: 31/4/1386 [pii] 10.1523/JNEUROSCI.4570-10.2011. 
Merleau-Ponty, M., Phenomenology of Perception, London, Routledge \& Kegan Paul, 1962.

Metzinger, T. (ed.), Neural Correlates of Consciousness: Empirical and Conceptual Questions, Cambridge, MA, MIT Press, 2000.

Miller, G.A., Psychology: The Science of Mental Life, New York, NY, Harper \& Row, 1962.

Miller, G.A., 'Computation, Consciousness, and Cognition', Behavioral and Brain Sciences, vol. 3, no. 1, 1980, p. 146.

Mnih, V. et al., 'Human-level Control through Deep Reinforcement Learning', Nature, vol. 518, no. 7540, 2015, pp. 529-33, DOI: 10.1038/nature14236.

Muckli, L. et al., 'Contextual Feedback to Superficial Layers of V1', Current Biology, vol. 25, no. 20, 2015, pp. 2690-95, DOI: 10.1016/j.cub.2015.08.057.

Nagel, T., 'What is it Like to be a Bat?', Philosophical Review, no. 83, 1974, pp. 435-50.

Neisser, U., Cognition and Reality: Principles and Implications of Cognitive Psychology, New York, NY, Freeman, 1976.

Owen, A.M., N.D. Schiff and S. Laureys, 'A New Era of Coma and Consciousness Science', Progress in Brain Research, no. 177, 2009, pp. 399-411, DOI: 10.1016/S0079-6123(09)17728-2. 
Pascual-Leone, A. and V. Walsh, 'Fast Backprojections from the Motion to the Primary Visual Area Necessary for Visual Awareness', Science, vol. 292, no. 5516, 2001, pp. 510-12, DOI: 10.1126/science.1057099.

Pinto, Y. et al., 'Expectations Accelerate Entry of Visual Stimuli into Awareness', Journal of Vision, vol. 15, no. 8, 2015, 13, DOI: 10.1167/15.8.13.

Rosenthal, D.M., Consciousness and Mind, Oxford, Clarendon Press, 2005.

Salti, M. et al., 'Distinct Cortical Codes and Temporal Dynamics for Conscious and Unconscious Percepts', eLife, 2015, DOI: 10.7554/eLife.05652.

Schachter, S. and J.E. Singer, 'Cognitive, Social, and Physiological determinants of Emotional State', Psychological Review, no. 69, 1962, pp. 379-99.

Schartner, M. et al., 'Complexity of Multi-Dimensional Spontaneous EEG Decreases during Propofol Induced General Anaesthesia', PLOS One, vol. 10, no 8, 2015, e0133532, DOI: 10.1371/journal.pone.0133532 (accessed 31 January 2016).

Scoville, W.B. and B. Milner, 'Loss of Recent Memory after Bilateral Hippocampal Lesions. 1957', Journal of Neuropsychiatry \& Clinical Neurosciences, vol. 12, no. 1, 2000, pp. 103-13.

Searle, J., 'Minds, Brains, and Programs', Behavioral and Brain Sciences, vol. 3, no. 3, 1980, pp. 417-57. 
Seth, A.K., 'Explanatory Correlates of Consciousness: Theoretical and Computational Challenges', Cognitive Computation, vol. 1, no. 1, 2009, pp. 50-63.

Seth, A.K., 'The Strength of Weak Artificial Consciousness', Journal of Machine Consciousness, vol. 1 , no. 1, 2009, pp. 71-82.

Seth, A.K., 'The Grand Challenge of Consciousness', Frontiers in Psychology, vol. 1, no. 5, 2010, pp. 1-2.

Seth, A.K., 'Interoceptive Inference, Emotion, and the Embodied Self', Trends in Cognitive Sciences, vol. 17, no. 11, 2013, pp. 565-73, DOI: 10.1016/j.tics.2013.09.007.

Seth, A.K., 'Darwin's Neuroscientist: Gerald M. Edelman, 1929-2014', Frontiers in Psychology, vol. 5, 2014, 896, DOI: 10.3389/fpsyg.2014.00896.

Seth, A.K., 'A Predictive Processing Theory of Sensorimotor Contingencies: Explaining the Puzzle of Perceptual Presence and its Absence in Synesthesia', Cognitive Neuroscience, vol. 5, no. 2, 2014, pp. 97-118, DOI: $10.1080 / 17588928.2013 .877880$.

Seth, A.K., 'The Cybernetic Bayesian Brain: From Interoceptive Inference to Sensorimotor Contingencies', in J.M. Windt and T. Metzinger (eds.), Open MIND, Frankfurt am Main, MIND Group, 2015, pp. 1-24.

Seth, A.K., 'Editorial', Neuroscience of Consciousness, no. 1, 2015, pp. 1-3. 
Seth, A.K., A.B. Barrett and L. Barnett, 'Causal Density and Integrated Information as Measures of Conscious Level', Philosophical Transactions of the Royal Society A: Mathematical, Physical, and Engineering Sciences, vol. 369, no. 1952, 2011, pp. 3748-67, DOI: 10.1098/rsta.2011.0079.

Sierra, M. and A.S. David, ‘Depersonalization: A Selective Impairment of Self-awareness’, Consciousness and Cognition, vol. 20, no. 1, 2011, pp. 99-108, DOI:

10.1016/j.concog.2010.10.018.

Sitt, J.D. et al., 'Large Scale Screening of Neural Signatures of Consciousness in Patients in a Vegetative or Minimally Conscious State', Brain, vol. 137, pt. 8, 2014, pp. 2258-70, DOI: 10.1093/brain/awu141.

Slater, M. et al., 'First Person Experience of Body Transfer in Virtual Reality', PLOS One, vol. 5, no. 5, 2010, e10564, DOI: 10.1371/journal.pone.0010564.

Summerfield, C. and F.P. de Lange, 'Expectation in Perceptual Decision Making: Neural and Computational Mechanisms', Nature Reviews Neuroscience, vol. 15, no. 11, 2014, pp. 745-56, DOI: $10.1038 / \mathrm{nrn} 3838$.

Super, H., H. Spekreijse and V.A. Lamme, 'Two Distinct Modes of Sensory Processing Observed in Monkey Primary Visual Cortex (V1)', Nature Neuroscience, vol. 4, no. 3, 2001, pp. 304-10, DOI: $10.1038 / 85170$.

Sutherland, S., International Dictionary of Psychology, New York, NY, Crossroad Classic, 1989. 
Thompson, E., 'Life and Mind: From Autopoeisis to Neurophenomenology: A Tribute to Francisco Varela', Phenomenology and the Cognitive Sciences, no. 3, 2004, pp. 381-98.

Tononi, G., 'Consciousness as Integrated Information: A Provisional Manifesto', Biological Bulletin, vol. 215, no. 3, 2008, pp. 216-42.

Tononi, G. and G.M. Edelman, 'Consciousness and Complexity', Science, vol. 282, no. 5395, 1998, pp. 1846-51.

Tononi, G. and C. Koch, 'The Neural Correlates of Consciousness: An Update', Annals of the New York Academy of Sciences, no. 1124, 2008, pp. 239-61.

Tononi, G. and C. Koch, 'Consciousness: Here, There and Everywhere?', Philosophical Transactions of the Royal Society of London B: Biological Sciences, vol. 370, no. 1668, 2015, DOI: 10.1098/rstb.2014.0167.

Tsuchiya, N. et al., 'No-Report Paradigms: Extracting the True Neural Correlates of Consciousness', Trends in Cognitive Sciences, vol. 19, no. 12, 2015, pp. 757-70, DOI: 10.1016/j.tics.2015.10.002.

van Gaal, S. and V.A. Lamme, 'Unconscious High-level Information Processing: Implication for Neurobiological Theories of Consciousness', Neuroscientist, vol, 18, no. 3, 2012, pp. 287-301, DOI: $10.1177 / 1073858411404079$. 
van Kerkoerle, T. et al., 'Alpha and Gamma Oscillations Characterize Feedback and Feedforward Processing in Monkey Visual Cortex', Proceedings of the National Academy of Sciences of the USA, vol. 111, no. 40, 2014, pp. 14332-41, DOI: 10.1073/pnas.1402773111.

Varela, F., E. Thompson and E. Rosch, The Embodied Mind: Cognitive Science and Human Experience, Cambridge, MA, MIT Press, 1993.

Watson, J.B., 'Psychology as the Behaviorist Views it', Psychological Review, no. 20, 1913, pp. 158-77.

Weinberger, J., 'William James and the Unconscious: Redressing a Century-old Misunderstanding', Psychological Science, vol. 11, no. 6, 2000, pp. 439-45.

Young, R.M., Mind, Brain, and Adaptation in the Nineteenth Century, New York, NY, Oxford University Press, 1991. 